\title{
Tissue sulfomucin and sialomucin content in colon mucosa without intestinal transit subjected to intervention with Curcuma longa (curcumin) ${ }^{1}$
}

Antonio José Tiburcio Alves Júnior', José Aires Pereira", Adrieli Heloísa Campardo Pansani"', Daniela Oliveira Magro'v, Cláudio Saddy Rodrigues Coyv, Carlos Augusto Real Martinez ${ }^{\mathrm{V}}$

'Fellow Master degree, Postgraduate Program in Surgical Sciences, Universidade Estadual de Campinas (UNICAMP), Brazil. Intellectual and scientific content of the study; acquisition, analysis and interpretation of data.

"PhD, Assistant Professor, Division of Pathology, Universidade São Francisco University (USF), Bragança Paulista-SP, Brazil. Acquisition, analysis and interpretation of data; histological examinations.

"'Undergraduate student, Medical School, USF, Bragança Paulista-SP, Brazil. PIBIQ/CNPq scholarship holder. Acquisition, analysis and interpretation of data.

IVPhD, Assistant Professor, Division of Nutrition, UNICAMP, Campinas-SP, Brazil. Acquisition and interpretation of data, statistical analysis.

'PhD, Associate Professor, Head, Department of Surgery, UNICAMP, Campinas-SP, Brazil. Acquisition, analysis and interpretation of data; manuscript preparation.

VIPhD, Associate Professor, USF and UNICAMP, Brazil. Grant from National Council for Scientific and Technological Development (CNPq), Ministry of Science, Scientific Productivity, Level 2. Intellectual and scientific content of the study, conception and design of the study, manuscript writing.

\section{Abstract}

Purpose: To measure the tissue sulfomucin and sialomucin content of the colon mucosa without fecal flow, subjected to intervention with curcumin, and the influence of the concentration used and the intervention time.

Methods: Thirty-six rats were subjected to proximal right colostomy and distal mucous fistula. They were divided into two groups according to whether sacrifice was performed two or four weeks after the intervention. Each group was divided into three subgroups according to the enema applied daily: saline alone; curcumin at $50 \mathrm{mg} / \mathrm{kg} /$ day or curcumin at $200 \mathrm{mg} /$ $\mathrm{kg} /$ day. Acid mucins were diagnosed using the Alcian blue technique. The mucin content was quantified by means of computer-assisted image analysis. The significance level of $5 \%$ was used throughout $(p<0.05)$.

Results: There were dose-related increases in the quantities of sulfomucins in the animals subjected to interventions with curcumin, both after two weeks $(p<0.00001)$ and after four weeks ( $p<0.00001)$. There were increases in sialomucin quantity that were concentrationrelated $(p<0.00001)$ and time-related $(p<0.00001)$.

Conclusion: Curcumin enemas increase the quantity of acid mucins in the intestinal flow in the excluded colon, with dose and time dependency.

Key words: Colitis. Curcumin. Mucins. Sialomucins. Rats. 


\section{- Introduction}

The mucosa of the colon functions as a protective barrier that separates the large quantities of bacteria, antigens and toxins present inside the intestinal lumen from the sterile environment ${ }^{1-4}$. This mucosal barrier promotes protection that is both mechanical and immunological ${ }^{5-6}$. The mechanical protection consists mainly of the mucus layer that covers the epithelium, cytoplasmic membranes, intercellular junction systems and basal membrane $\mathrm{e}^{5-6}$. The immunological barrier is provided by different defense cells, which make the intestine the biggest lymphoid organ in the human body.

The mucus barrier that covers the colon mucosa is the first line of defense. This layer provides protection against the trauma resulting from fecal transit and also has bacteriostatic and bactericidal action. The mucus that covers the intestinal epithelium is formed mostly by mucins, which are molecules composed of both a carbohydrate fraction and a protein fraction. In the carbohydrate portion of the molecule, the mucins belong to two main groups: neutral and acid types ${ }^{1-7}$. In turn, the acid mucins consist of two subtypes, according to whether sulfate radicals (sulfomucins) or sialic acid radicals (sialomucins) predominate in the molecule ${ }^{1}$.

The tissue expression of mucins has been found to be altered in different intestinal illnesses, and particularly in intestinal infectious diseases, inflammatory bowel diseases (IBD) and colorectal cancer. A series of experimental studies has demonstrated that the tissue mucin content in colon segments excluded from the intestinal transit becomes modified. Colitis of the excluded colon is a form of IBD that affects segments of the large intestine that have been deprived of intestinal transit8. The pathogenesis of colitis of the excluded colon has been correlated with deficiency of regular supply of short-chain fatty acids (SCFA) to the cells of the colonic epithelium consequent to intestinal exclusion ${ }^{9-16}$. These experimental studies have also shown that cells that have been deprived of SCFA supply undergo modification of their energy metabolism, with consequently greater production of oxygen free radicals (OFRs). When OFRs are not neutralized by the antioxidant systems of the colon mucosa, they damage the mechanical protection of the mucosa, particularly the mucus layer that covers the surface of the epithelium $^{6,17}$.

It has been shown that application of enemas containing natural or synthetic substances with antioxidant effect is capable of reducing the inflammation of the mucosa of the excluded colon ${ }^{8,18-19}$. One such substance is curcumin, an extract from Curcuma Longa, to which a variety of medicinal properties have been attributed. Curcumin is extracted from the rhizome of this plant and is recognized for its prominent effect of removal of OFRs that are formed during inflammatory responses [20]. Because of its anti-inflammatory and antioxidant action, it has been used to treat different illnesses that involve IBD ${ }^{21-24}$.

The oxidative stress in colitis of the excluded colon that results from increased production of OFRs modifies the content and expression pattern of the carbohydrate fraction of the mucins of epithelial glands ${ }^{5,17}$. Moreover, Curcuma longa possesses proven antioxidant effects ${ }^{20}$. In this light, it becomes a matter of interest to ascertain the effects of applying curcumin enemas to the content and expression pattern of acid mucins and their subtypes. However, to the best of our knowledge, this evaluation has not yet been conducted.

Thus, the objective of the present study was to evaluate the content and expression pattern of acid mucins in the mucosa of the colon after exclusion from fecal transit and 
application of enemas containing curcumin. The study also aimed to ascertain whether the effect of this substance was related to the concentration used and the duration of the intervention.

\section{- Methods}

The experiments were performed in accordance with the principles outlined in Federal Law no. 11.794 (August 10, 2008) and were approved by the Ethics Committee for Animal Research, Universidade São Francisco (approval no. 2211/2007).

Thirty-six male Wistar rats (weighing 300-350g) were obtained from the animal colony of the School of Medicine, USF. They were kept under conditions of light/dark cycles of 12 hours each, and were fed a standard rodent chow diet. They were deprived of food, but not water, for $24 \mathrm{~h}$ prior to the surgical procedure.

\section{Surgical technique}

Diversion of the fecal flow was performed in all animals under general anesthesia that was attained through intramuscular administration of $0.1 \mathrm{ml} / 100 \mathrm{~g}$ of a $1: 1(\mathrm{v} / \mathrm{v})$ solution of ketamine (50 $\mathrm{mg} / \mathrm{ml}$ ) and xylazine $(20 \mathrm{mg} / \mathrm{ml})$. The abdomen was shaved, and a $3 \mathrm{~cm}$-long midline incision was made. The left colon was exteriorized and sectioned in its mid-portion, corresponding to the descending colon, approximately $3 \mathrm{~cm}$ above Peyer's lymphoid patch (which is located at the rectal-sigmoid transition). Two circular skin pellets, $3 \mathrm{~mm}$ in diameter and $3 \mathrm{~cm}$ apart, were made in the left side of the abdominal wall at the same vertical level. The proximal end of the colon was exteriorized through the cranial cutaneous orifice, and the distal stoma was exteriorized through the caudal skin opening after splitting the abdominal wall muscles. The proximal end and the distal stoma were fixed to the skin with full-thickness sutures. Before fixation of the distal stoma to the skin, the distal colon was cleaned by means of infusion of a physiological solution until the fecal contents had been completely removed. The abdominal incision was closed in two stages: aponeurosis and skin. Thus, two colostomies were performed: a proximal colostomy, as a terminal colostomy with intestinal transit; and a second colostomy, as a distal stoma devoid of fecal flow. The rats were kept in individual cages, without any particular care taken with regard to the stomas and abdominal incisions.

\section{Experimental groups}

Figure 1 shows the division of the experimental groups. The animals were divided into two experimental groups with 18 animals each, according to whether the animals would be sacrificed after two or four weeks. Each experimental group was divided into six subgroups $(n=6)$ according to the intervention used and duration of intervention. In the first and second subgroups, 12 animals received daily rectal enemas containing $20 \mathrm{ml}$ of $0.9 \%$ saline solution (control subgroup) at 37 으 for two weeks $(n=6)$ or four weeks $(n=6)$. In the second subgroup, 12 animals received daily rectal enemas containing $20 \mathrm{ml}$ of curcumin (SigmaAldrich, St Louis, MO, USA) at a concentration of $50 \mathrm{mg} / \mathrm{kg}$ for two weeks ( $\mathrm{n}=6$ ) or four weeks $(n=6)$. Finally, 12 animals in the third subgroup received daily enemas containing $20 \mathrm{ml}$ of curcumin at a concentration of $200 \mathrm{mg} / \mathrm{kg}$ for two weeks $(n=6)$ or four weeks $(n=6)$. In order to standardize the speed of application and the time taken to do it, the enemas for all animals were administered using an infusion pump for which the speed had been standardized at 20/ $\mathrm{ml} / \mathrm{min}$. 


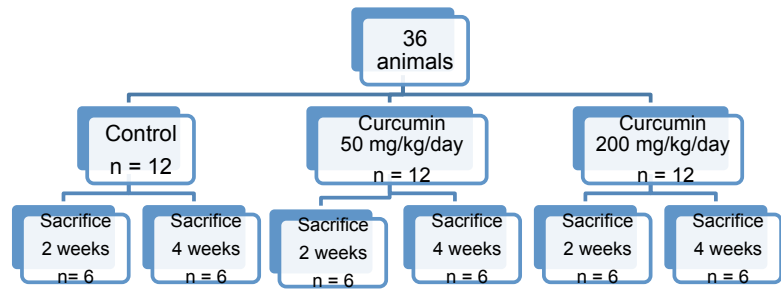

Figure 1 - Subdivision of the experimental groups.

\section{Sample collection}

Upon completion of the predetermined irrigation period, the animals were anesthetized as described above, and the midline incision was opened again. In both groups, specimens were taken from the intraabdominal part of the excluded colon without fecal flow, which had been subjected to irrigation using the proposed substances. The specimen removed, measuring approximately $4.0 \mathrm{~cm}$, was opened longitudinally through the antimesenteric border, while fixed to a piece of cork, and was then sent for histological and histochemical analysis. The animals were sacrificed with an intracardiac lethal dose of thiopental and the carcasses were incinerated.

\section{Histological and histochemical analysis}

Fragments prepared for histological analysis were immersed in $10 \%$ neutral formalin buffer (Sigma-Aldrich, St. Louis, MO, USA) for $24 \mathrm{~h}$, dehydrated by means of exposure to increasing ethanol concentrations, and embedded in paraffin. Tissue sections of thickness $5 \mu \mathrm{m}$ were then cut using a rotary microtome (Leica Biosystems, Nussloch, Germany), mounted on glass slides, cleared, hydrated and stained with hematoxylin-eosin (HE) for evaluation of the presence of colitis. The analysis on the slides was performed under an optical microscope (Eclipse DS-50, Nikon
Inc., Osaka, Japan) with final magnification of $x 200$. Photomicrographs were taken using a digital video-capture camera (DS-Fi-50; Nikon Inc., Osaka, Japan) coupled to the microscope body. The images were digitized by means of a computer system for image analysis (NISElements; Nikon Inc., Osaka, Japan).

The diagnosis of colitis was made based on the presence of three independent histological parameters: reduction of the crypt length, neutrophil infiltration of the mucosa and epithelial loss. These variables were stratified as crosses, according to the degree of each variable, as follows: a) + absent or no alterations; b) ++ when intensity was mild; c) +++ moderate; and d) ++++ intense. For all variables analyzed, the final value considered for each animal was the mean value after quantification of three distinct histological fields.

The tissue acid mucin expression was determined individually by means of the Alcian blue $(A B)$ histochemical technique. The total acid mucin content stained blue. To identify the subtypes of acid mucins (sulfomucins and sialomucins), the slides were stained using the high iron diamine-Alcian blue (HID-AB) histochemical technique, in accordance with the standardized methodology. In summary, the slides were deparaffinized in two successive xylol baths for 10 minutes, treated with an alcohol rinse in three successive baths of pure alcohol and then hydrated in running water for five minutes. After this step, they were washed in three successive baths of distilled water and then exposed to high-iron diamine (HID) for six hours. The HID solution consisted of $120 \mathrm{mg}$ of NN-dimethylmeta-phenylenediamine-dihydrochloride, 20 $\mathrm{mg}$ of $\mathrm{NN}$-dimethyl-paraphenylenediaminedihydrochloride, $50 \mathrm{ml}$ of distilled water and $1.4 \mathrm{ml}$ of a recently prepared solution of $60 \%$ ferric chloride. At the end of the HID staining, the sections were washed in running water 
for five minutes and then in three successive baths of distilled water. Subsequently, they were exposed to the staining agent Alcian blue $(A B)$ for 10 minutes and then washed in running water for five minutes followed by three successive baths of distilled water. The $1 \% A B$ staining medium was prepared in acetic acid ( $\mathrm{pH} 2.5)$. At the end of this step, the slides were counterstained with neutral red for eight minutes and washed again in running water. They were then dehydrated in three successive baths of pure alcohol and diaphanized in three baths of xylol, and cover slips were mounted using resin. Through the HID-AB technique, sulfomucins stained brown and sialomucins stained blue. A pathologist with expertise in diseases of the digestive tract, who was unaware of the origin of the material and objectives of the study, evaluated the presence of colitis and the pattern of tissue expression.

\section{Computer-assisted image processing}

The tissue acid mucin content (sulfomucins and sialomucins) was quantified by means of computer-assisted image processing and was always performed in a focal field in which there were at least three complete and contiguous colonic crypts, at a magnification of $x 200$. The images selected were captured on a video camera that had been coupled to an optical microscope. These images were processed and analyzed using the NIS-Elements 3.1 software (Nikon Inc., Osaka, Japan), installed in a microcomputer. By means of colored histograms in the red, green and blue (RGB) system, the software determined the color intensity and the number of pixels in each selected field, and the final data were transformed into percentage expression per field analyzed (\%/field). The final value measured for each section was the mean of the values found from evaluating three different fields. The presence of sulfomucins and sialomucins was quantified in the same glands.

\section{Statistical analysis}

The statistical analysis on the results obtained was conducted using a significance level of $5 \%$ ( $p \leq 0.05)$. The data from each colon segment analyzed in each experimental group were expressed as the mean value with the respective standard error and were analyzed using the Biostat for Windows statistical software (version 5.0).

\section{Results}

There was no reduction in the inflammatory score in animals submitted to intervention with curcumin at a dose of 50 $\mathrm{mg} / \mathrm{kg}$ and $200 \mathrm{mg} / \mathrm{kg}$ for two weeks when compared to animals submitted to saline intervention. A decrease in the inflammatory score was founded in colon segments without fecal stream submitted to intervention with oil extract of curcumin at concentration of $200 \mathrm{mg} / \mathrm{kg}$ for four week when compared with animals submitted to intervention with saline.

Figure 2 shows the sulfomucin content found in the colon segments without fecal flow after intervention with saline or 50 $\mathrm{mg} / \mathrm{kg} /$ day or $200 \mathrm{~g} / \mathrm{kg} /$ day of curcumin oil extract over a two or four-week period. The results show that intervention with curcumin oil extract at a concentration of $50 \mathrm{mg} / \mathrm{kg} /$ day or $200 \mathrm{~g} / \mathrm{kg} /$ day in a colon devoid of fecal flow significantly increased the sulfomucin content two or four weeks after irrigation, compared with animals in the control group $(p<0.01)$. The results also show that intervention with curcumin oil extract at a concentration of 200 $\mathrm{mg} / \mathrm{kg} /$ day in colon segments devoid of fecal flow significantly increased the sulfomucin content two or four weeks after irrigation, compared with animals subjected to irrigation at a concentration of $50 \mathrm{mg} / \mathrm{kg} /$ day. 


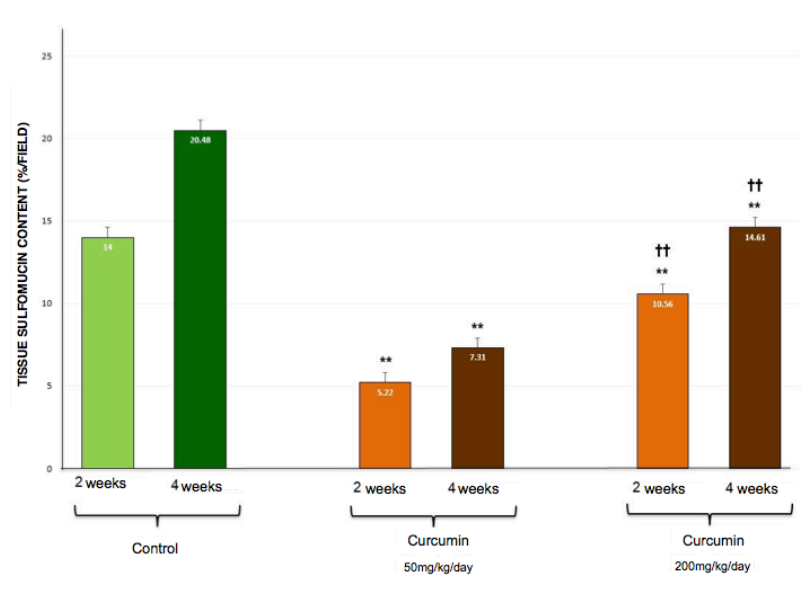

Figure 2 - Tissue sulfomucin content after interventions using $0.9 \%$ physiological serum, curcumin $(50 \mathrm{mg} / \mathrm{kg} /$ day) and curcumin $(200 \mathrm{mg} /$ $\mathrm{kg} /$ day), after two or four weeks. ${ }^{* *}=$ significant ( $\mathrm{p}$ $<0.01$ ) curcumin $>0.9 \%$ physiological serum; $\dagger^{+}=$ significant $(p<0.01)$ curcumin $(200 \mathrm{mg} / \mathrm{kg} /$ day $)>$ curcumin ( $50 \mathrm{mg} / \mathrm{kg} /$ day). Mann Whitney test.

Figure 3 shows the tissue sialomucin content found in the segments without fecal flow after interventions using saline and 50 $\mathrm{mg} / \mathrm{kg} /$ day and $200 \mathrm{mg} / \mathrm{kg} /$ day of curcumin oil extract after two or four weeks. The results show that intervention with curcumin oil extract at a concentration of $50 \mathrm{mg} / \mathrm{kg} / \mathrm{day}$ significantly increased the sialomucin content four weeks after irrigation compared with animals in the control group and with animals subjected to intervention with curcumin at same concentration after two weeks. The intervention with curcumin oil extract at a concentration of $200 \mathrm{mg} / \mathrm{kg} /$ day significantly increased the sialomucin content two or four weeks after irrigation, compared with animals in the control group $(p<0.01)$ and animals subjected to intervention at concentration of $50 \mathrm{mg} / \mathrm{kg} /$ day, after two or four weeks ( $\mathrm{p}<$ 0.01).

Table 1 shows the mean values with the corresponding standard errors for the variation in the tissue total acid mucin content (sulfomucins and sialomucins) in animals subjected to interventions using saline and curcumin oil extracts at concentrations of 50 $\mathrm{mg} / \mathrm{kg} /$ day and $200 \mathrm{mg} / \mathrm{kg} /$ day according to the duration of the intervention (two or four weeks).

It can be seen that the quantities of both subtypes (sulfomucins and sialomucins) were higher after four weeks, independent of the intervention substance used.

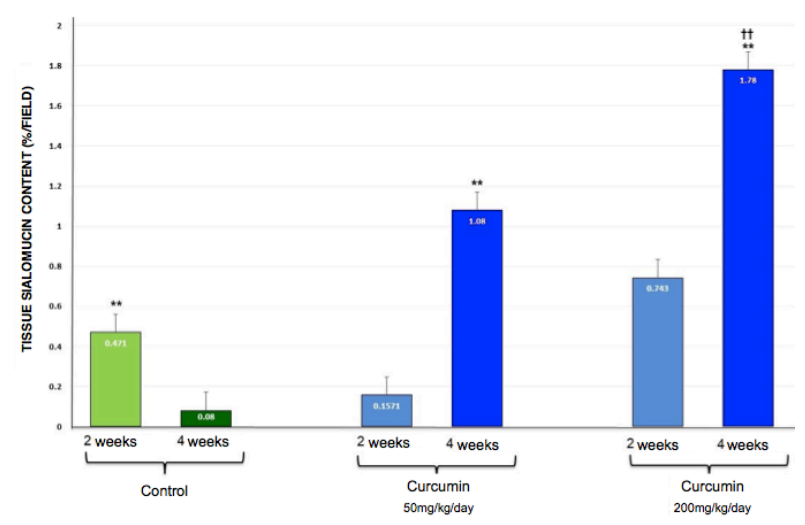

Figure 3 - Tissue sialomucin content after interventions using $0.9 \%$ physiological serum, curcumin $(50 \mathrm{mg} / \mathrm{kg} /$ day) and curcumin $(200 \mathrm{mg} /$ $\mathrm{kg} /$ day), after two or four weeks. ${ }^{* *}=$ significant ( $\mathrm{p}$ $<0.01$ ) curcumin $>0.9 \%$ physiological serum; $\dagger^{\dagger}=$ significant $(p<0.01)$ curcumin $(200 \mathrm{mg} / \mathrm{kg} /$ day $)>$ curcumin $(50 \mathrm{mg} / \mathrm{kg} /$ day). Mann Whitney test. 
Table 1 - Influence of the duration of the intervention on tissue sulfomucin and sialomucin expression in the animals subjected to interventions using $0.9 \%$ physiological serum and curcumin oil extract at concentrations of $50 \mathrm{mg} / \mathrm{kg} /$ day and $200 \mathrm{mg} / \mathrm{kg} /$ day.

\begin{tabular}{|c|c|c|c|}
\hline \multirow{2}{*}{$\begin{array}{l}\text { Intervention substance and } \\
\text { concentration }\end{array}$} & \multicolumn{2}{|c|}{ Mean \pm standard error } & \multirow[t]{2}{*}{$p$ value } \\
\hline & 2 weeks & 4 weeks & \\
\hline \multicolumn{4}{|l|}{ Sulfomucins } \\
\hline Control & $14.0 \pm 0.32$ & $20.48 \pm 0.24$ & $<0.0001$ \\
\hline Curcumin $(50 \mathrm{mg} / \mathrm{kg} /$ day $)$ & $5.22 \pm 0.39$ & $7.31 \pm 0.61$ & $<0.004$ \\
\hline Curcumin (200 mg/kg/day) & $10.56 \pm 0.36$ & $14.61 \pm 0.49$ & $<0.0001$ \\
\hline \multicolumn{4}{|l|}{ Sialomucins } \\
\hline Control & $0.471 \pm 0.06$ & $0.080 \pm 0.01$ & $<0.0001$ \\
\hline Curcumin $(50 \mathrm{mg} / \mathrm{kg} /$ day $)$ & $0.157 \pm 0.03$ & $1.08 \pm 0.12$ & $<0.0001$ \\
\hline Curcumin $(200 \mathrm{mg} / \mathrm{kg} /$ day $)$ & $0.743 \pm 0.09$ & $1.781 \pm 0.09$ & $<0.0001$ \\
\hline
\end{tabular}

Table 2 compares the quantities of sulfomucin and sialomucin expressed in the tissue of the colon segment deprived of intestinal transit, after specific interventions using $0.9 \%$ physiological serum, curcumin (50 mg/kg/day) and curcumin (200 mg/kg/ day), taking into account the intervention substance and the dose used. It can be seen that the quantities of both acid mucins were greater after the intervention with $200 \mathrm{mg} / \mathrm{kg} /$ day of curcumin, with statistically significant differences.

Table 2 - Influence of the concentration used on tissue sulfomucin and sialomucin expression in the animals subjected to interventions using $0.9 \%$ physiological serum and curcumin oil extract at concentrations of $50 \mathrm{mg} / \mathrm{kg} /$ day and $200 \mathrm{mg} / \mathrm{kg} /$ day, after two or four weeks of intervention.

\begin{tabular}{lcccc} 
& \multicolumn{4}{c}{ Mean \pm standard error } \\
\cline { 2 - 5 } $\begin{array}{l}\text { Intervention } \\
\text { and concentration }\end{array}$ & $\begin{array}{c}0.9 \% \\
\text { shysiological } \\
\text { serum }\end{array}$ & $\begin{array}{c}\text { Curcumin } \\
50 \mathrm{mg} / \mathrm{kg} / \text { day }\end{array}$ & $\begin{array}{c}\text { Curcumin } \\
200 \mathrm{mg} / \mathrm{kg} / \text { day }\end{array}$ & p value \\
\hline $\begin{array}{l}\text { Sulfomucins } \\
\quad \text { Two weeks }\end{array}$ & $14.0 \pm 0.32$ & $5.22 \pm 0.39$ & $10.56 \pm 0.36$ & $<0.00001$ \\
$\quad$ Four weeks & $20.48 \pm 0.24$ & $7.31 \pm 0.61$ & $14.61 \pm 0.49$ & $<0.00001$ \\
\hline Sialomucins & & & & \\
$\quad$ Two weeks & $0.471 \pm 0.06$ & $0.157 \pm 0.03$ & $0.743 \pm 0.09$ & $<0.0004$ \\
$\quad$ Four weeks & $0.08 \pm 0.01$ & $1.08 \pm 0.12$ & $1.78 \pm 0.09$ & $<0.0001$ \\
\hline
\end{tabular}

ANOVA test.

Sulfomucins: two weeks: $0.9 \%$ physiological serum > curcumin $(50 \mathrm{mg} / \mathrm{kg} /$ day $) ; 0.9 \%$ physiological serum $>$ curcumin $(200 \mathrm{mg} / \mathrm{kg} /$ day); curcumin ( $200 \mathrm{mg} / \mathrm{kg} /$ day) > curcumin $(50 \mathrm{mg} / \mathrm{kg} /$ day). Four weeks: $0.9 \%$ physiological serum > curcumin $(50 \mathrm{mg} / \mathrm{kg} /$ day); $0.9 \%$ physiological serum > curcumin ( $200 \mathrm{mg} / \mathrm{kg} /$ day); curcumin $(200 \mathrm{mg} / \mathrm{kg} /$ day $)>$ curcumin $(50 \mathrm{mg} / \mathrm{kg} /$ day) .

Sialomucins: two weeks: $0.9 \%$ physiological serum versus curcumin $(50 \mathrm{mg} / \mathrm{kg} /$ day); $0.9 \%$ physiological serum versus curcumin $(200$ $\mathrm{mg} / \mathrm{kg} /$ day); curcumin $(200 \mathrm{mg} / \mathrm{kg} /$ day) versus curcumin $(50 \mathrm{mg} / \mathrm{kg} /$ day). Four weeks: $0.9 \%$ physiological serum < Curcuma longa (50 $\mathrm{mg} / \mathrm{kg} /$ day); $0.9 \%$ physiological serum versus Curcuma longa ( $200 \mathrm{mg} / \mathrm{kg} /$ day); Curcuma longa $(50 \mathrm{mg} / \mathrm{kg} /$ day) versus Curcuma longa (200 mg/kg/day). 
Figures 4 to 6 compare the sulfomucin and sialomucin content found in the colon segments without fecal flow after intervention with saline or $50 \mathrm{mg} / \mathrm{kg} /$ day or $200 \mathrm{~g} / \mathrm{kg} /$ day of curcumin oil extract over a four-week period.

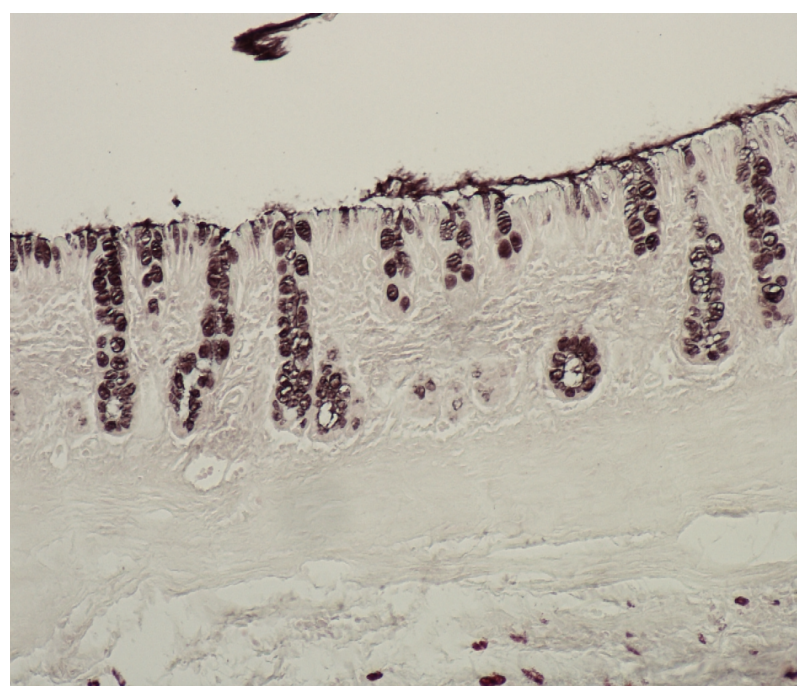

Figure 4 - Colon segment without fecal flow after intervention with saline over a four-week period.

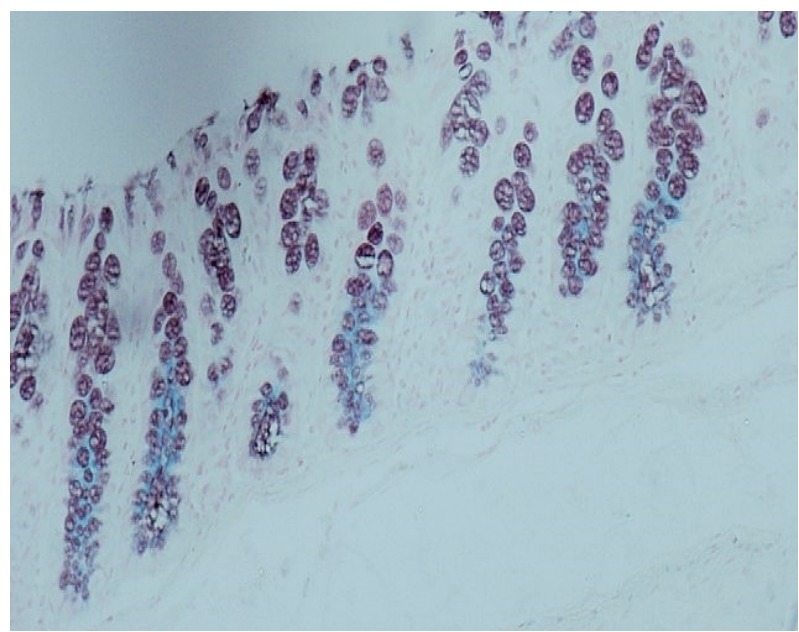

Figure 5 - Colon segment without fecal flow after intervention with $50 \mathrm{mg} / \mathrm{kg} /$ day of curcumin oil extract over a four-week period.

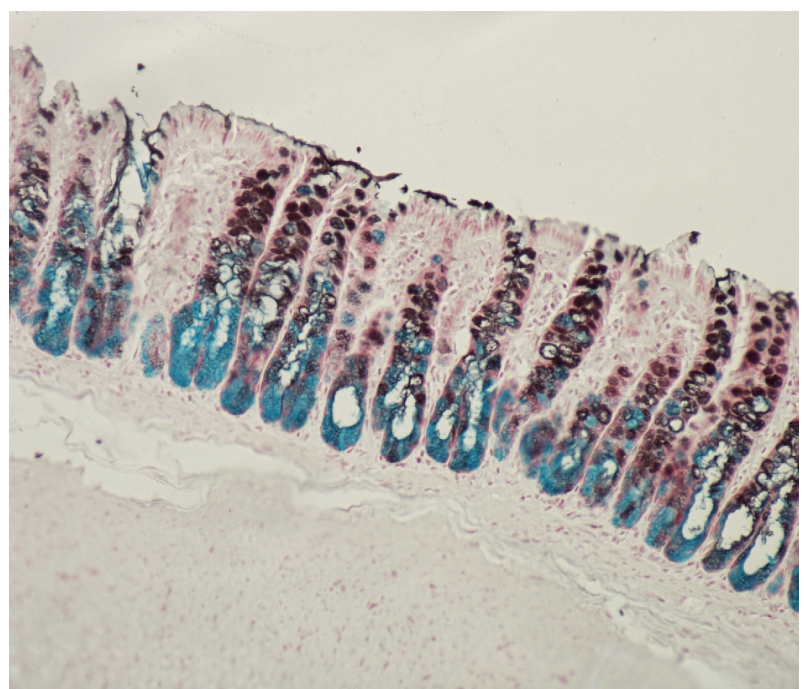

Figure 6 - Colon segment without fecal flow after intervention with $200 \mathrm{mg} / \mathrm{kg} /$ day of curcumin oil extract over a four-week period.

\section{Discussion}

Given that the main factor responsible for colitis appearing in the excluded colon is OFRs, many studies on antioxidant substances have been conducted. OFRs have been shown to be effective in animal models ${ }^{18}$. Studies on curcumin in the ulcerative colitis (UC) have been conducted and have shown benefits both in rats and in humans. Sugimoto et $a .^{25}$ used curcumin mixed into the feed administered to rats in which colitis had been induced using trinitrobenzene sulfonic acid and observed that a histological improved occurred. In humans, Holt et al. ${ }^{21}$ administered curcumin to five patients with Crohn's disease and UC, and observed that the clinical symptoms improved. Hanai et al. ${ }^{23}$ showed in a randomized study on individuals with UC that those who were administered curcumin and sulfasalazine together maintained a more sustained clinical response than did those who received salicylate alone. Kumar et al. ${ }^{22}$ 
conducted the first systematic review of the literature and showed that curcumin was effective for sustaining the clinical condition of patients with $\mathrm{UC}^{21-23}$. Given the effective response of UC to curcumin, it is valid to suppose that it would also be effective in cases of colitis due to an excluded colon, considering that the clinical, endoscopic and histopathological characteristics of these two conditions are similar ${ }^{5-26}$.

It is noteworthy that most studies that have used curcumin have not demonstrated any toxicity and have shown negligible side effects when used on humans ${ }^{27}$. The fact that curcumin is insoluble in water should also be borne in mind, given that this makes its absorption within the gastrointestinal tract more difficult and leads to the need to administer high doses of curcumin in order to reach serum levels. Nonetheless, this medication has been found to attain high concentrations in the intestinal lumen, which corroborates the notion that topical action is perhaps more important than systemic action ${ }^{27}$.

There are several ways of evaluating tissue injury. It has been shown that the issue acid and neutral mucin content in intestinal segments deprived of transit is reduced, which has led to a belief that oxidative stress interferes with production of these proteins ${ }^{1,5}$. Nonose et $a{ }^{17}{ }^{17}$ demonstrated that deviation of the fecal transit diminished the expression of acid mucins in the segments deprived of intestinal transit and that this alteration in expression was time-dependent. They also reported that the quantities of sulfomucins and sialomucins were generally constant on the surface of the normal colon. However, inversion of their proportions is often considered to be a pathological alteration.

Given the clinical and histopathological similarities between colitis of an excluded colon and UC, it is conceivable to believe that evolution of chronic inflammatory processes to dysplasia and neoplasia may occur in cases of colitis of an excluded colon, just as occurs in IBD. Likewise, it is feasible to believe that quantification of sulfomucin and sialomucin expression in the colon mucosa may bea possible means of assessing the therapeutic efficacy of different substances that are used, including curcumin. The antioxidant action of this substance is thought to prevent development of dysplasia and subsequently, colorectal cancer ${ }^{17}$. However, it should be emphasized that the inverse presentation of acid mucin expression in IBD and colitis of an excluded colon, along with the increasing incidence of colorectal cancer among individuals with UC, suggests that other intraluminal factors may be involved in this distinct pattern of sulfomucin and sialomucin expression. It is possible that different pattern of tissue acid mucin expression may be related to lower possibility of neoplastic transformation ${ }^{5}$.

Given that curcumin has antioxidant effects and that it is a medication of low toxicity and negligible side effects, it would seem to be of interest to study its effects in relation to colitis of an excluded colon, with evaluation of its effects on the pattern of acid mucin expression in the excluded colon segment.

This study had the aims of quantifying the tissue sulfomucin and sialomucin content in the mucosa of colon segments that had been deprived of fecal transit and ascertaining whether the quantity of acid mucins underwent any change after an intervention using curcumin. It was found that application of enemas of curcumin at concentrations of 50 $\mathrm{mg} / \mathrm{kg} /$ day and $200 \mathrm{mg} / \mathrm{kg} /$ day considerably increased the total acid mucin content of the colon segment that had been deprived of fecal transit, compared with a group of animas that was treated with $0.9 \%$ physiological serum. It is possible that the improvement in the inflammatory score levels and the increase in the sulfomucines and sialomucins content 
found in the animals submitted to intervention with oil extract of curcumin in higher concentration may be related to the lower oxidative tissue stress due to the lower degree of neutrophil infiltrate.This corroborates our previous studies in the same group of animals that showed that curcumin had protective antioxidant and anti-inflammatory effects reducing the neutrophil infiltrate evaluated by immunohistochemistry tissue expression of myeloperoxidase1,28.

Previous studies that quantified the tissue acid mucin expression in situations of exclusion colitis in rats found that there was a significant reduction in sulfomucin and sialomucin content. This gives further value to the findings of the present study. It is believed that reduction of acid mucin levels, particularly sialomucins, is related to absence of SCFA5,17.

It was also observed that the tissue quantities of sialomucins and sulfomucins became greater with higher doses of curcumin administered, and with longer periods of treatment. Thus, the results from the present study seem to confirm information from previous studies that showed that curcumin had a protective effect on the colon epithelium and which indirectly demonstrated that OFRs may have a role in the physiopathology of colitis of an excluded colon.

\section{Conclusions}

Topical application of curcumin enemas to colon segments that had been excluded from fecal transit increased the tissue quantities of sulfomucins and sialomucins, which demonstrated that this therapy had a protective effect. This study also showed that the action of curcumin was dose and timedependent.

\section{References}

1. Keli E, Bouchoucha M, Devroede G, Carnot F, Ohrant T, Cugnenc PH. Diversion-related experimental colitis in rats. Dis Colon Rectum.
1997;40:222-8. PMID: 9075761

2. Pereira JA, Rodrigues MR, Sato DT, Silveira Junior PP, Dias AM, Silva CG, Martinez CAR. Evaluation of sucralfate enema in experimental diversion colitis. J Coloproctol. 2013;33(4):182-90. doi: 10.1016/j. jcol.2013.08.005.

3. Chaim FDM, Sato DT, Rodrigues MR, Silveira Junior PP, Pereira JA, Martinez CA. Evaluation of the application of enemas containing sucralfate in tissue content of neutral and acidis mucins in experimental model of diversion colitis. Acta Cir Bras. 2014;29:54452. PMID: 25252200.

4. Bonassa CEG, Pereira JA, Campos FGCM, Rodrigues MR, Daniela TS, Chaim FDM, Martinez CA. Tissue content of sulfomucins and sialomucins in the colonic mucosa, without fecal stream, undergoing daily intervention with sucralfate. Acta Cir Bras. 2015;30(5):328-38. PMID: 26016932.

5. Martinez CAR, Nonose R, Spadari APP, Maximo FR, Priolli DG, Pereira JA, Margarido NF. Quantification by computerized morphometry of tissue levels of sulfomucins and sialomucins in diversion colitis in rats. Acta Cir Bras. 2010;25:231-40. PMID: 20498935.

6. Martinez CAR, Ribeiro ML, Gambero $A$, Miranda DDC, Pereira JA, Nadal SR. The importance of oxygen free radicals in the etiopathogenesis of diversion colitis in rats. Acta Cir Bras. 2010;25:387-95. PMID: 20877947.

7. Deplancke B, Gaskins HR. Microbial modulation of innate defense: goblet-cells and the intestinal mucus layer. Am J Clin Nutr. 2001;73:1131S-41S. PMID: 11393191.

8. Glotzer DJ, Glick ME, Goldman H. Proctitis and colits following diversion of fecal stream. Gastroenterology. 1981;80(3):438-41. PMID: 7450438.

9. Bosshardt RT, Abel ME. Proctitis following fecal diversion. Dis Colon Rectum. 1984;27(9):6057. PMID: 6468202.

10. Agarwal VP, Schimmel EM. Diversion colitis: a nutritional deficiency syndrome? Nutr Rev. 1989;47(9):257-61. PMID: 2689929.

11. Harig JM, Soergel KH, Komorowsky RA, Wood CM. Treatment of diversion colitis with short-chain-fatty acid irrigation. N Engl J Med. 1989;320(1):23-8. PMID: 2909876.

12. Ferguson CM, Siegel RJ. A prospective 
evaluation of diversion colitis. Am Surg. 1991;57(1):46-9. PMID: 1796797.

13. Geraghty JM, Talbot IC. Diversion colitis: histological features in the colon and rectum after defunctioning colostomy. Gut. 1991;32(9):1020-3. PMID: 1916483.

14. Haque $S$, West AB. Diversion colitis--20 years a-growing. J Clin Gastroenterol. 1992;15(4): 281-3. PMID: 1294631.

15. Mortensen PB, Clausen MR. Short-chain fatty acids in the human colon: relation to gastrointestinal health and disease. Scand J Gastroenterol. 1996;216:132-48. PMID: 8726286.

16. Cook SI, Sellin JH. Review article: short-chain fatty acids in healthy and disease. Aliment Pharmacol Ther. 1998; 12(6):499-507. PMID: 9678808.

17. Nonose R, Spadari APP, Priolli DG, Maximo FR, Pereira JA, Martinez CA. Tissue quantification of neutral and acid mucins in the mucosa of the colon with and without fecal stream in rats. Acta Cir Bras. 2009;24:267-75. PMID: 19705025.

18. Caltabiano C, Maximo FR, Spadari APP, Da Conceição Miranda DD, Serra MM, Ribeiro ML, Martinez CA. 5-aminosalicylic acid (5-ASA) can reduce levels of oxidative DNA damage in cells of colonic mucosa with and without fecal stream. Dig Dis Sci. 2011;56(4):1037-46. PMID: 21042854.

19. Martinez CA, de Almeida MG, da Silva CM, Ribeiro ML, da Cunha FL, Rodrigues MR, Sato DT, Pereira JA. Enemas with N-acetylcysteine can reduce the level of oxidative damage in cells of the colonic mucosa diverted from the faecal stream. Dig Dis Sci. 2013;58(12):34529. PMID: 23828143.

20. Fu Y, Zheng S, Lin J, Ryerse J, Chen A. Curcumin protects the rat liver from $\mathrm{CCl} 4$-caused injury and fibrogenesis by attenuating oxidative stress and suppressing inflammation. Mol Pharmacol. 2008;73(2):399-409. PMID: 18006644.

21. Holt PR, Kattz S, Kirshoff R. Curcumin therapy in inflammatory bowel disease: a pilot study.
Dig Dis Sci. 2005;50(11):2191-3. PMID: 16240238.

22. Kumar S, Ahuja V, Sankar MJ, Kumar A, Moss AC. Curcumin for maintenance of remission in ulcerative colitis. Cochrane Database Syst Rev. 2012;17(10):CD008424. PMID: 23076948.

23. Hanai $H$, Ilda $T$, Takeuchi $K$, Watanabe F, Maruyama Y, Andoh A, Tsujikawa T, Fujiyama Y, Mitsuyama K, Sata M, Yamada M, Iwaoka Y, Kanke K, Hiraishi H, Hirayama $\mathrm{K}$, Arai H, Yoshii S, Uchijima M, Nagata T, Koide $Y$. Curcumin maintenance therapy for ulcerative colitis: randomized, multicenter, double-blind, placebo-controlled trial. Clin Gastroenterol Hepatol. 2006;4(12):1502-6. PMID: 17101300.

24. Lang, A, Salomon N, Wu JC, Kopylov U, Lahat A, Har-Noy O, Ching JY, Cheong PK, Avidan B, Gamus D, Kaimakliotis I, Eliakim R, Ng SC, Ben-Horin S. Curcumin in combination with mesalamine induces remission in patients with mil-to-moderate ulcerative colitis in a randomized controlled trial. Clin Gastroenterol Hepatol. 2015;13(8):1444-50. PMID: 25724700.

25. Sugimoto K, Hanai H, Tozawa K, Aoshi T, Uchijima M, Nagata T, Koide Y. Curcumin prevents and ameliorates trinitrobenzene sulfonic acid-induced colitis in mice. Gastroenterology. 2002;123(6):1912-22. PMID: 12454848.

26. Pravda J. Radical induction theory of ulcerative colitis. World J Gastroenterol. 2005;11(16):2371-84. PMID: 15832404.

27. Vecchi BL, Marcuzzi A, Tricarico PM, Zanin V, Girardelli M, Bianco AM. Curcumin and inflammatory bowel disease: potential and limits of innovative treatments. Molecules. 2014;19(12):21127-53. PMID: 25521115.

28. Kadri CJ, Pereira JA, Campos FG, Ortega MM, Bragion CB, Martinez CA. Anti-inflammatory effects of enemas containing an oily extract of curcumin in an experimental model of diversion colitis. Histol Histopathol. 2017 Feb;32(2):161-9. doi: 10.14670/HH-11-783. 


\section{Correspondence:}

Antonio José Tiburcio Alves Júnior Rua Sacramento, 1032/144

13010-210 Campinas - SP Brasil antonio_xxxv@yahoo.com.br

Received: Nov 07, 2016

Review: Jan 09, 2017

Accepted: Feb 06, 2017
Conflict of interest: none

Financial source: FAPESP (Grant: 2006/023066)

${ }^{1}$ Research performed at Laboratory of Medical Investigation, Universidade São Francisco (USF), Bragança Paulista-SP, Brazil. Part of Master degree thesis, Postgraduate Program in Surgical Sciences, Universidade Estadual de Campinas (UNICAMP). Tutor: Carlos Augusto Real Martinez. 